\title{
Lingual Nerve
}

National Cancer Institute

\section{Source}

National Cancer Institute. Lingual Nerve. NCI Thesaurus. Code C127835.

A branch of the mandibular division of the trigeminal nerve that supplies sensory innervation to the tongue. 